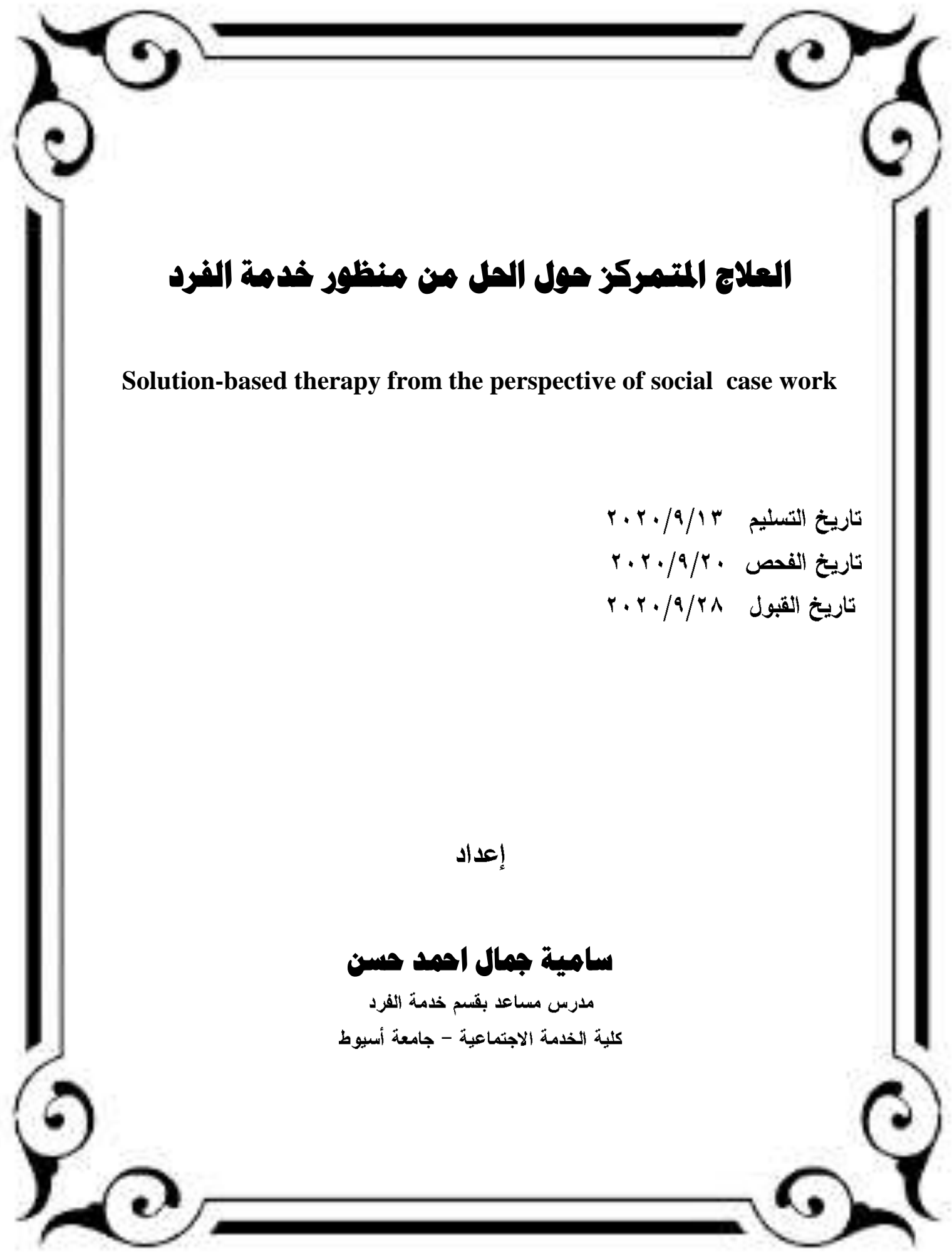





\section{العلاج المتمركز حول الحل من منظور خدمة الفرد}

\section{اعداد - - اد

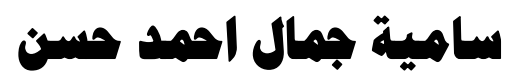

مدرس مساعد بقسم خدمة الفرد

كلية المخدمة الاجتماعية - جامعة أسيوط

بحثت هذه الاراسة بشكل نظري في اسلوب العلاج المتمركز حول الحل من منظور خدمة الفرد، من حيث

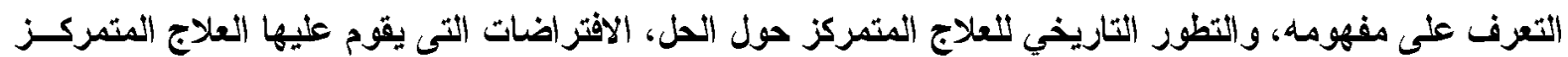
حول الحل، و تكنيكات العلاج المتمركز حول الحل، مبادى العلاج المتمركز حول الحل ، استراتيجيات العلاج المتمركز حول الحل ، التذخل المهنى بأستخدام العلاج المتمركز حول الحل ، أيضًا التعرف على المهارات المهنية للاخصــائيين

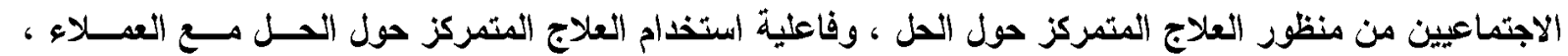

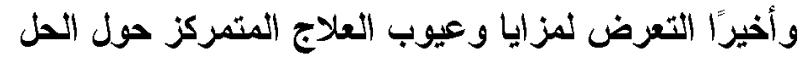

الكامات المفتاهية : العلاج المتمركز حول الحل - خدمة الفرد 


\begin{abstract}
This study theoretically examined the solution- based therapy from the perspective of social case work, in terms of identifying its concept, the historical development ofsolution-based therapy, the assumptions on which solution-based therapy, techniques solution-based therapy, principles solution-based therapy, strategies solution- based therapy, professional intervention using of solution-based therapy, also identification of the professional skills of social workers from the perspective of solution-based therapy, the effectiveness of using solution-based therapy with clients, and finally exposure to the advantages and disadvantages of solution- based therapy.
\end{abstract}

Keywords: solution- based therapy, Social Case Worke 
العلاج المتهركز حول الملل من منظور خدمة الفرد

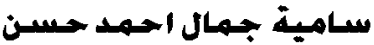

ثانيا- التطور التاريخي للعلاج المتهركز جهول
المجلة العلمية للخذمة الاجتماعية

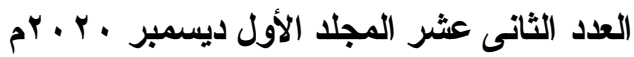

- مفهوم العلاج المتمركز حول الحل: نثأ العلاج المتمركز حول الحل فى عام . 19 1و وقــ

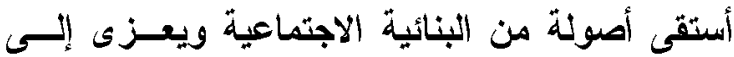
جهود كل من ستيف دي شنازر وانسو كيم في مركــز

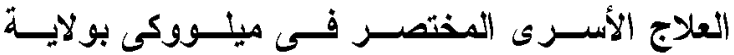
ويسكونسن الأمريكية، وعلى الزغم من حداثثة فــإن التطبيقات العلية والأسهامات البحثية حول التكنيكات التى يقدمها ومدي ملاعمتها في التعامل مـــع الفئـات

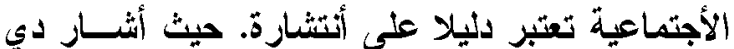

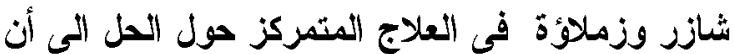
العملاء يعرفون بالفعل ما يجب القيام به لحل المشكلة ، واكنهم لا يعرفون سوي أنهج يعرفون ويالتالى فدور

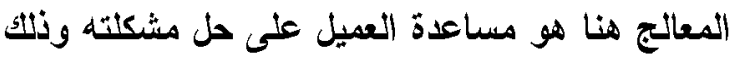
بأستخدام المعرفة التى لديهم.

(S. Smtth , 2009,104 )

حيث أعتقد دي شازر وبيزغ أن محاولة فهم المشكلة

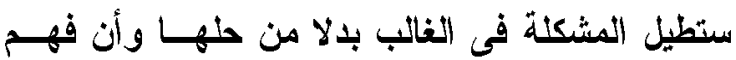

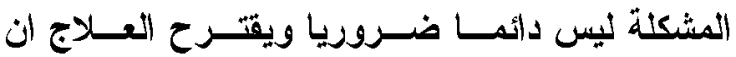
لايرتبط الحل بالمشكلة.

(F. P. Bannink, 2007, 1)

وفي عام ؛191ا نشــرت العليـــــن

المقالات للتوجة نـــو أســتـذام العـلاج المتمركـز

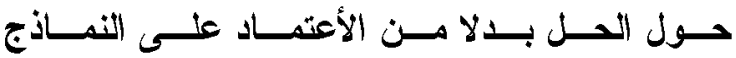

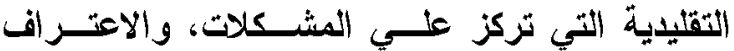
بأن العدلاء يمكنهم في كثيـر مــن الأحيــان إنثـــاء استر اتيجيات خاصة بهم للتغيير. (J ohn Wheeler, 2001, 293) وفي عام 1919 وضع دي شنازر مجموعـة مسن المبادي الأساسية للعلاج المتمركز حول الحل وتتثثل

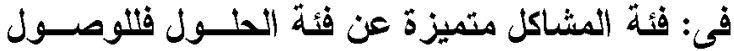
إلى الحل ليس من الضروري تحليل المثكلة ، ولكن من الضروري تحليل حلول العملاء ،العميل هو الخبيز

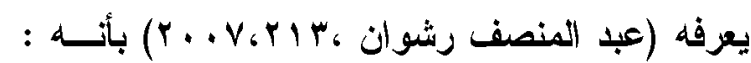

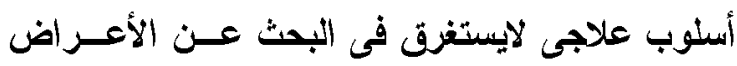

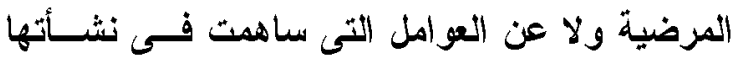

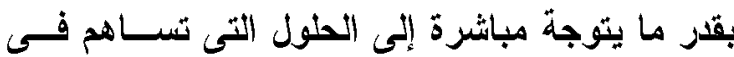

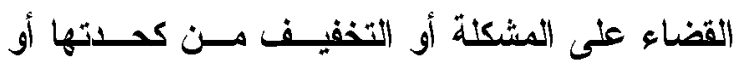
التكيف مع أقر ازاتها. كما يعرف بأنه نهج علاجى قصير الامد، يركز عنى أهداف العميل ، ويساعد العملاء على بناء الحلول بدلا من التركيز علــ المثــكلات. . Trepper, W.J) - ( Gingerich\&E.E. McCollum, 2012,13 كما عرفه (عبد المنصف حسن رشوان ،محد مسـفر

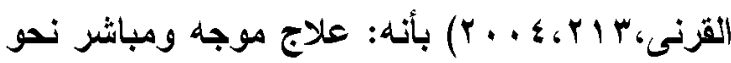
الهُف النهائى الذي يسعى له العميل وهو الوصسيول إلمى التوافق النفسي والاجتماعى مع الأت وهع البيئة

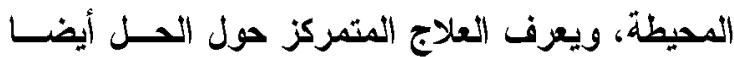

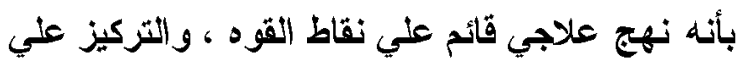

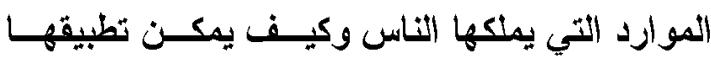
(Caroline Bond). لأحداث تغييزات ايجابيه لليهم .etal; 2013,707

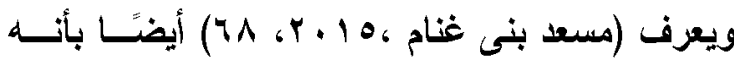
نموذج للعلاج النفسي المبني على الحل حيث يهــن

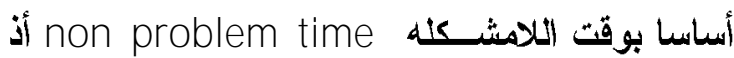

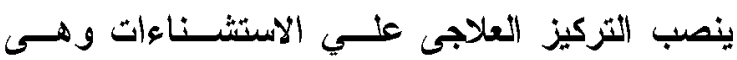

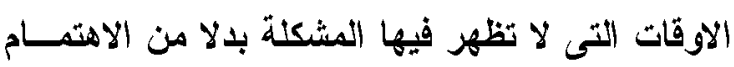

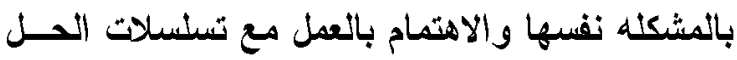
المحدد وتحديد الادوات والمصادر التى يملكها العدلاء

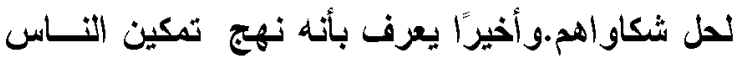

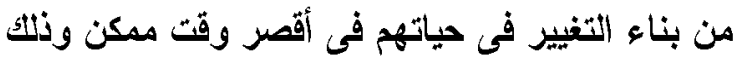
من خلال تشجيعهم علي وصف المسـتقبل المفضـل فل فيل

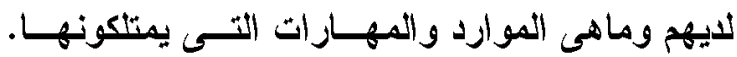
( Harvey Ratner etal; 2012,3) 
العلاج المتهركز حول المل من منظور خدمة الفرد

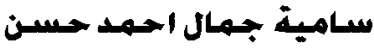

(Johnny S. Kim ,2014, 26)

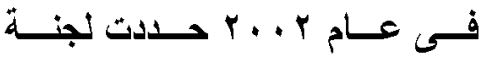

البحرث ثلاث مكونات للعلاج المتمركز حـول الحـل وهى استخدام المحادثات التي تركـز علــ مخــاوف

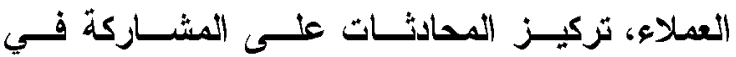
بنــاء معــاني جيـــة تعــيط بمخــارف العـــلاء،

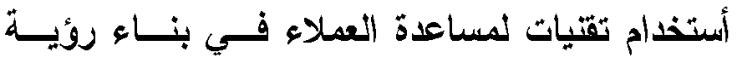
لمستقبل افضل والاستفادة مـن النجاحسات الســابقة ونقاط القوة لايهم للمساعدة في حل المشكلات. (Trepper, W.J. Gingerich\&E.E. McCollum, 2012.13:14) وفي عام V.... كتب ستيف دي شيزر ودولان عن العلاج المتمركز حول الحل بالتفصيل موضحين مسـي لـي

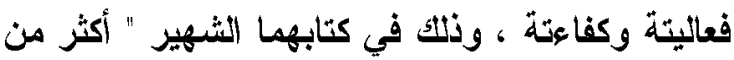
المعززات : حاله فن العلاج المختصر المتمركز حول

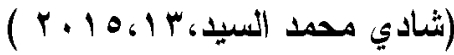

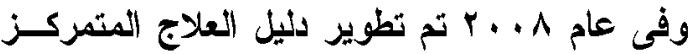
حول الحل لأول مرة وتحديثة في عامب ا +r من قبــل

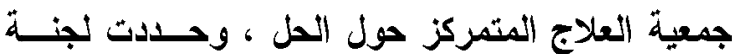

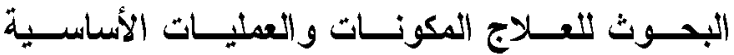
للمحادثات التى تعد مهمه للعلاج المتمركز حول الحل

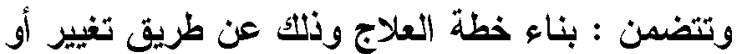
أنثاء معاني جديدة مع العدلاء حيث يتعاون المعـالج

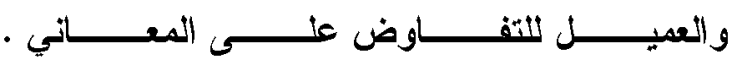
Cynthia Franklin and Anao Zhang, $(2016,2)$

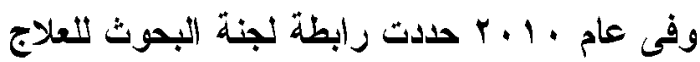

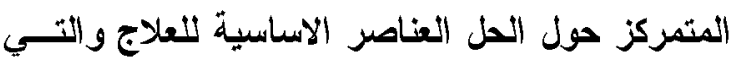
تتضمن التركيز علــى أهـــاف العيـلـل ،أســتخراج الاستثناءات من المشكية ، التعرف على قدرات العميل والموارد والادوات المستخدمة من ثبــل المعـالجين لاعني

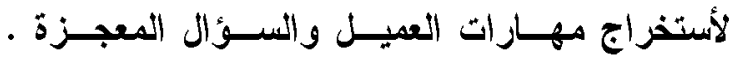
(Woods etal;, 2010,15)
عن مثكلته ، التركيز على التجارب الايجابيه في حياه

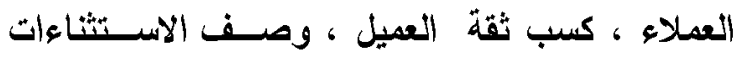
للمشكلة ، طرح اسئله: "ماذا تريد ان تري بلانلا هـن

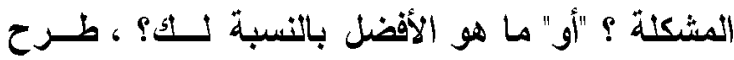

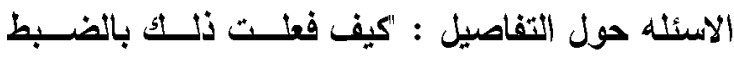
؟،إعطاء المكافات اللفظية وذلتك عن طريت المجاملات ، وفي نفس العام نشر دي شازر كتاب لــه بعــــان

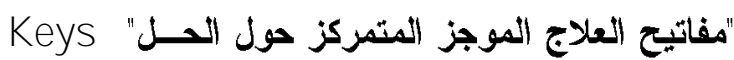
to Solution in Brief Therapy (Fredrike Bannink,2010,20)

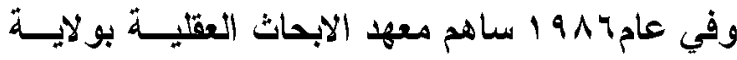
كاليفورنيا بالولايات الامريكية المتحدة بتطوير أساليب

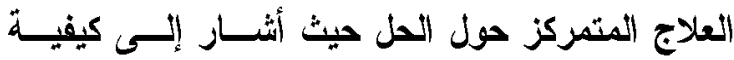

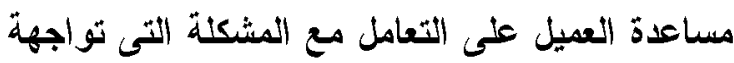
(EInora D. Cunanan, 2003, 8)

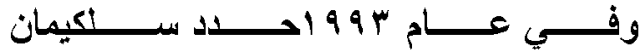
Selekman المثمركزة حول الحل وهي كالتالي : المقاومة كفكــة لاي العميل ليست مفيدة ، التعاون أمر حتمـي خـلال عملية العلاج، التغيير أمر لا مفر منه، لابد من حدوث

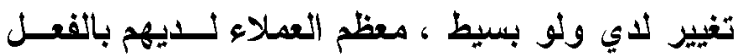

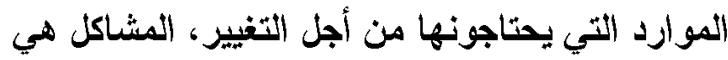

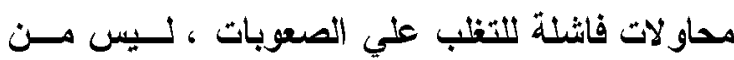

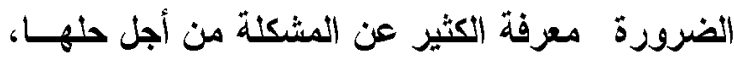

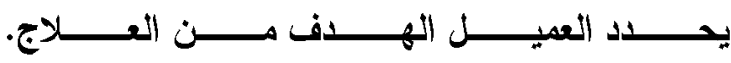
(Fredrike Bannink,2010,22: 26) وفي عام 199V نشـر دي شـــازر وأنســو كـيم

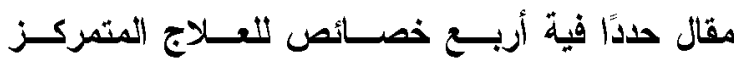

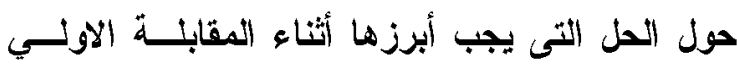
مع العميل وهي يجب على المعـالج طــرح الســؤال

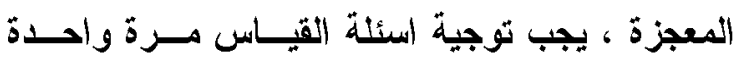

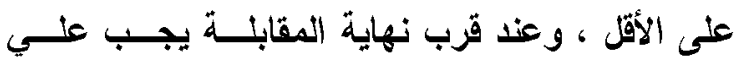

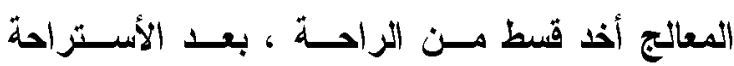
يعطي العميل مجموعة مسن الاقتراحسات أو المهــام المنزبية. 
العلاج المتهركز حول الملل من منظور خدمة الفرد

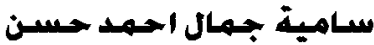

في المؤسسات ميع عدم تناسب الموارد الماليــة والبثرية لنلتص.

צ. ارتباط هذا العلاج بعلم النفس الاينامي ونظريسـة التحليل النفسي ويــري الــبعض أن أســـامات

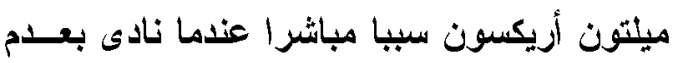

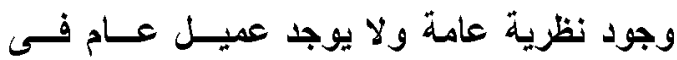
No general Theory, No مقولتة الشهيرة لطرديه general client الأعثماد علي نظرية واحدة في تفيسـر الســلوك

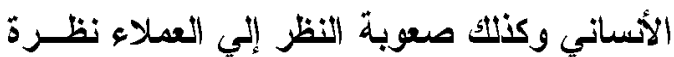
واحدة حتى لو كانت مثكلاههم متثابهة

ثالثــا- الأفتراضـات التــي يقـوم عليـهـا الهــلاج

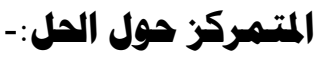

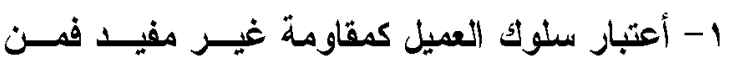

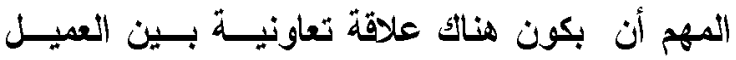
والمعالج بدلامن موقف المقاومة أو القوة أو السيطرة

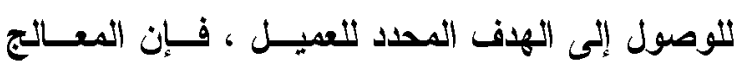

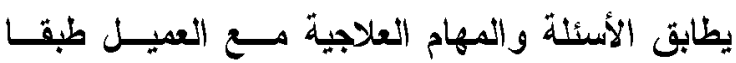

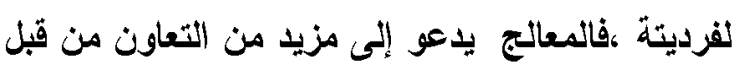

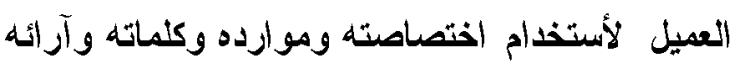
في حل المشكنة. r- التغيير أمر لا مفر منه ولا بد أن يحثث ويمكن أن

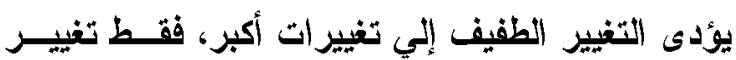
بسيط ضروري، بمجرد أن يتم تثبيع العميل لإثـــعار

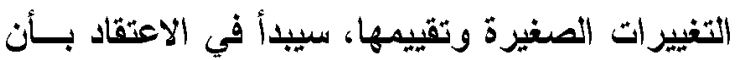

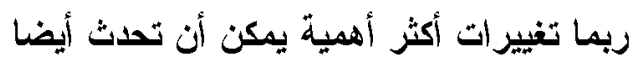

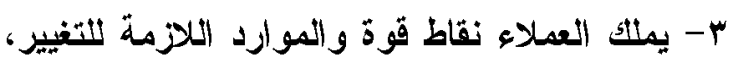
فكل شخص لايه قوة وموارد يمتلكها يمكن لنجاحسات سابقة للعميل أن تكون بمثابة نماذج للنجاحات الحالية والمستقبلية، وهنا يجب لفت إنتباة العميل إلي نقـاط لتحني

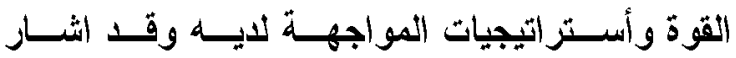
إريكسون إلى أهية أستخدام موارد العميل الخاصــة،

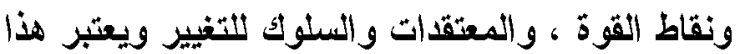
الاستخدام هو أساس العلاج المتمركز حول الحل .

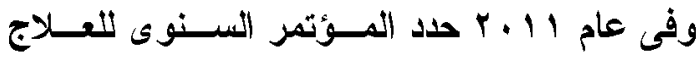

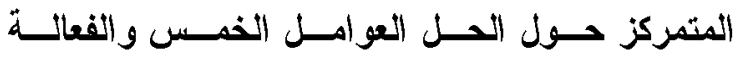
المستمدة دن البحوث المتراكمة والتى تؤدثى إلى قوة

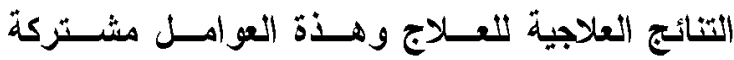

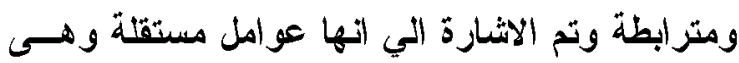
خصائص العميل، المعالج ، التحالف العلاجى ، الامال و التوقعات ، النموذج العلاجى.

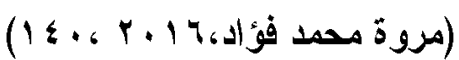
ويختلف العلاج المتمركز حول الحـل فــــ نــواحي

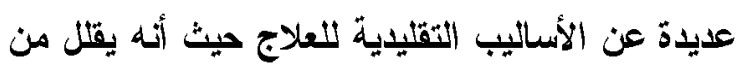

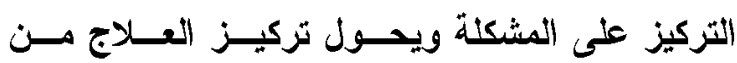
المشكلة إلى الحل، ويستكثـف المســتقبل المفضــل اللعميل، وماهي الحياة التـي ســكون عنــد حـدوث

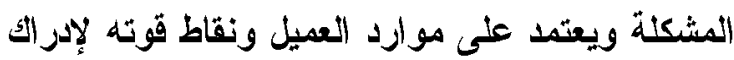
الحلول المستقبلية التي يركز عليها المعالجون لاتزكز

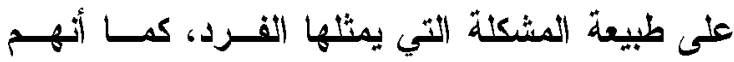

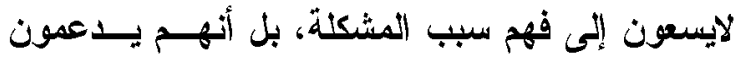

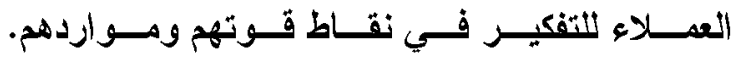

(Alison Nicholas,2014,210) وقد أسهمت العديد من العوامل فـى نشــأة وتطــور العلاج المتمركز حول الحل ونذكر منها ما يلي:

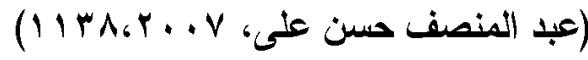

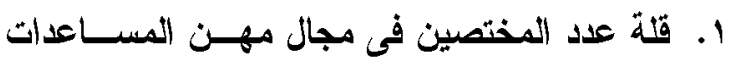
الأسانية وعلدم توافر الخبرة لاي البعض منهم.

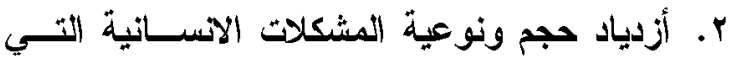
يعانى منها الافر اد والجماعات والمجتمعات نتيجة

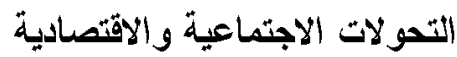
r. قلة عدد المؤسسات الاجتماعية التي تقدم أوجـة الاجئة

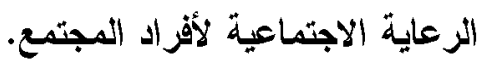

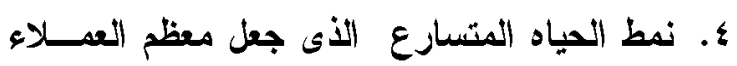

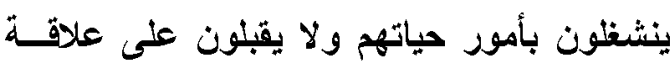

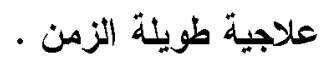

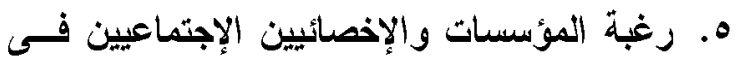
محاولة التكيف مع الأعداد المتزايدة من العمــلاء 
العلاج المتهركز حول المل من منظور خدمة الفرد

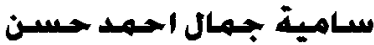

(Helen Lloyd\&

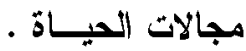

and Rudi Dallos, 2008 ,8)

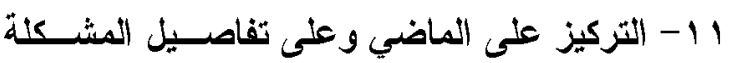

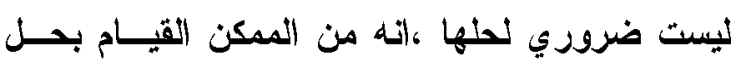
مثكلات العملاء من خلال التركيز على الجوانب التي

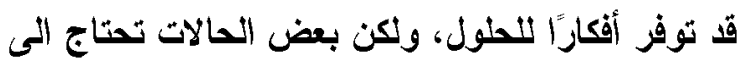
نقاش قتيل جدا حول المشكلة واسبابها، وعلى الرغم

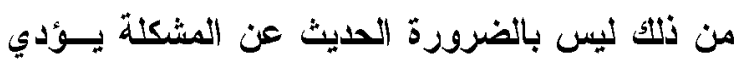

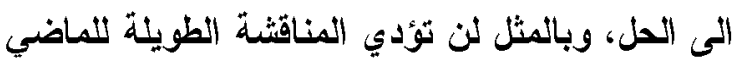

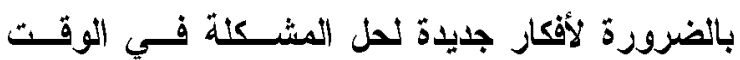
الحاضر، وربما تؤدي مناقثة الماضي إلــى مشــاعر

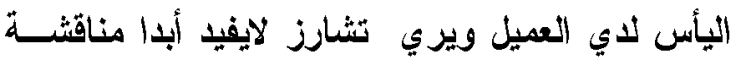

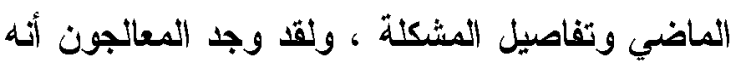

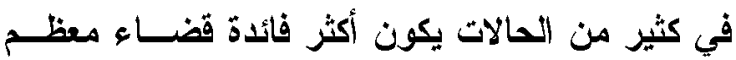

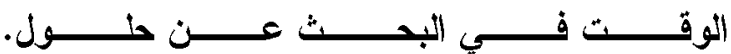
(John Rhodes \&Yasmin Ajmal, 1995,

r ا - تركز جلسة العلاج على الحاضر والمستقبل. با آ كل عميل فريد من نوعه

(Laura ع أ التعاون أمر حتمي.

M. Hopson etal, 2004,98) رابعا- تكنيكات العلاج المتهمركز حول الصل:

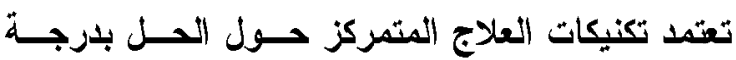
كبيرة علي مهارة الاخصائي الاجتماعي وعلي مسلدي

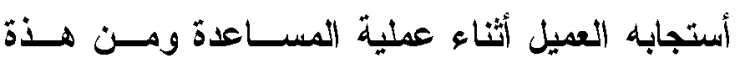
التكنيكات ما يلي :

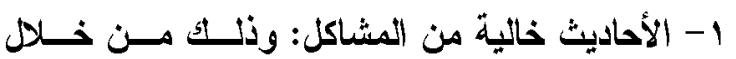

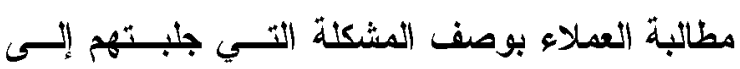

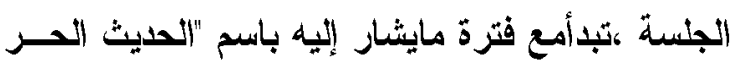

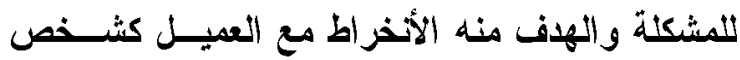

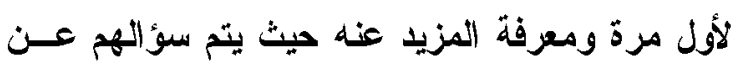

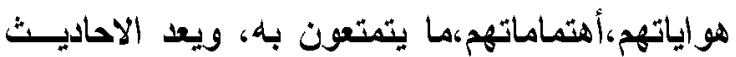

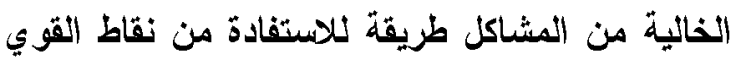
لاع العميل ومهار اتة ومواردة الثخصية ومن أكثــر

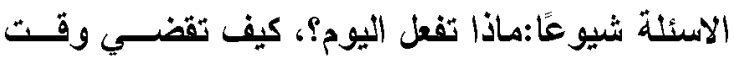

؟- لاتحتاج إلى معرفة الكثير عن المشـكلة لملهـا،

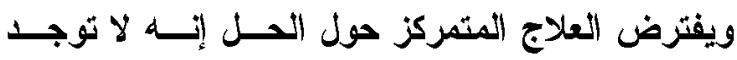

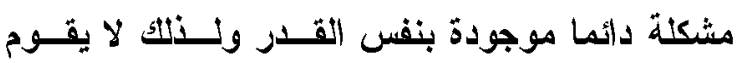

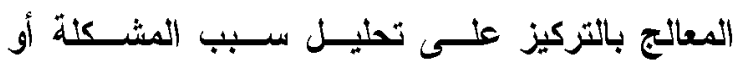

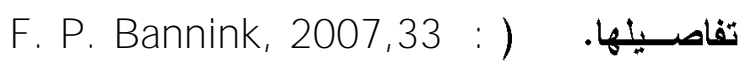
(34

ه- يحدد العميل هدف العلاج ويعتمد العـلاج عـــ اهداف العميل وليس على المعالج צ- العملاء هم الخبر اء حول حياتهم وخبر اتهم

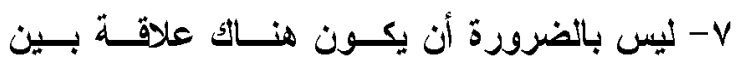

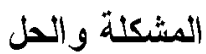

^- يجب على العملاء القيام بثـيء مختلف من أجـل

(Kevin

\section{Corcoran, Albert}

R.

Roberts,2015, 296)

9- تخضع المثاكل التصور العميل الفردي وتفسيره .

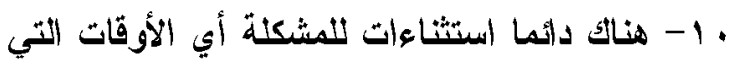
تكون فيها المشكلة أقل أو غائبة في جسوهر العـلاج يركز العلاج على شبكة من الأفكار جزئيا المســتمدة

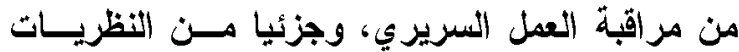

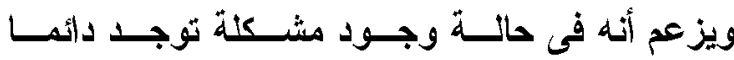
أستثناءات وهذا هو الاوقات التى تحثث فية المثــكة فئة بشكل أقل او تكون غائبة على الأطلاق ، حتى أذا كان

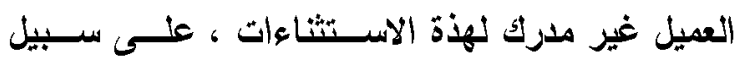
المثال الثخص المصاب بالأكتئاب قد يكون هنائك أيام

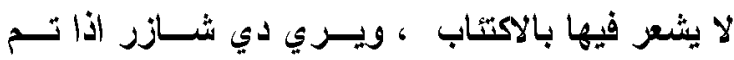

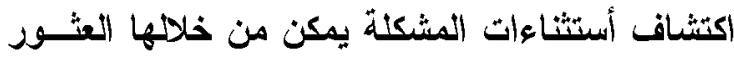

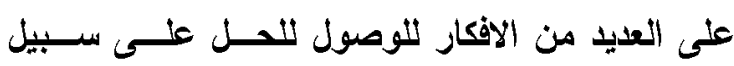

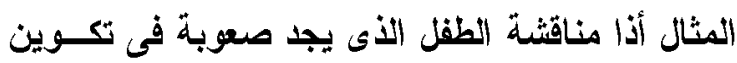

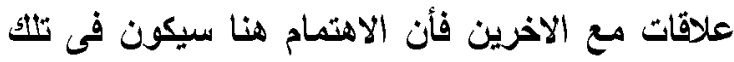

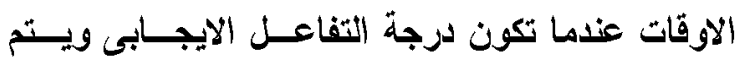

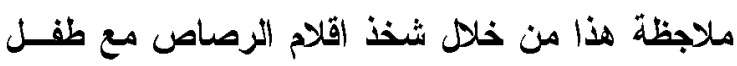

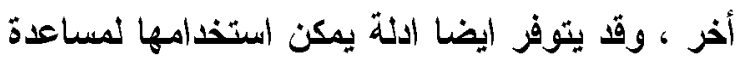

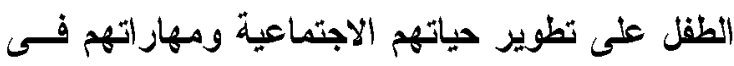


العلاج المتهركز حول المل من منظور خدمة الفرد

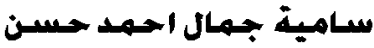

حتى لو كانت هذة النجاحات تمثل لحظات استثنائية في

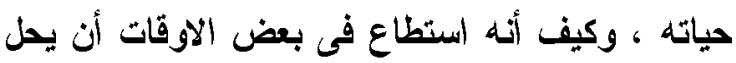

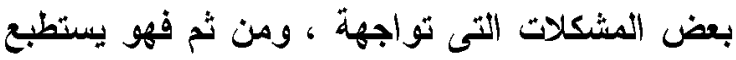

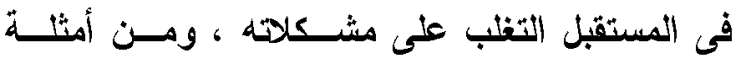

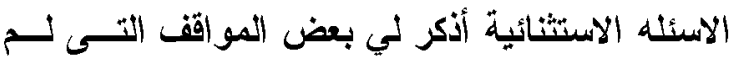

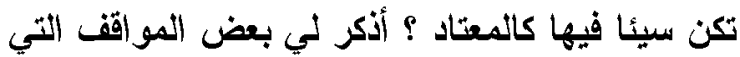

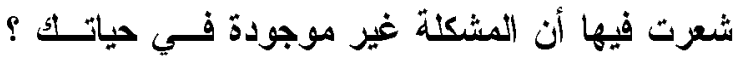

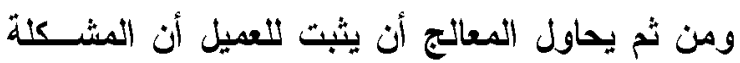

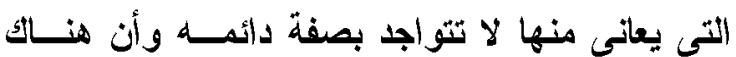

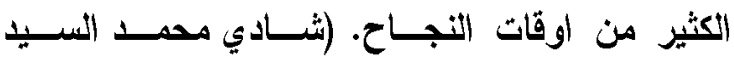

$(19.4+106$ ه- القياس: واحدة من أكثر التكنيكات المفيـدة فــي النهج الأي يركز على الحلول هي أســتخدام أســئة القياس. يُطلب من العميل التفكير في مقيـاس حيـث فئرئ يمثل • أ أفضل آماله المحققة و يمثل العكس. لايـتن استخدام أسئلة القياس كمقياس لمدى المشكلة ، بـل الـل يتم استخدامها لتحديد مكان العميـل عنــ المقيــاس بالنسبة إلى هدفه، والتعرف علـى الخطـــوات التــي اتخذها بالفعل والتي تسدح له بوضع نفسه في هـــه

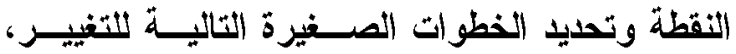
ويمكن أيضًا أستخدام أسئلة القياس لقياس التقدم إمسا من الجسة إلى الجلسة أو في باية مجموعة العـلاج وفي مواعيد المراجعة.

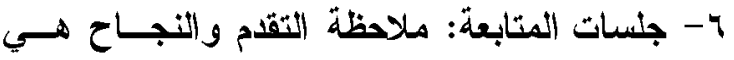
مهارة مهمة في الممارسة المتمركزة حول الحل وتبدأ جسات المتابعة بالسؤال: "مالأي سررت أن تلاحظه

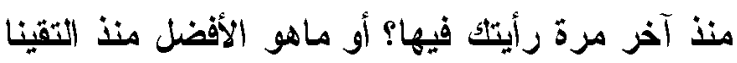
Alison Nicholas,2014, )

- V المهام المنزلية: وترتبط المهام المنزلية بأهــاف

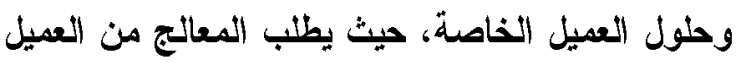

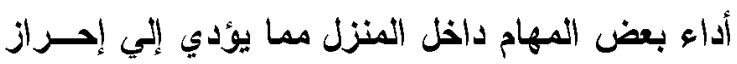
التقدم في العملية العلاجية فعندما يقوم العميل بالقيـام بالمهام المنزلية فإنه يقلا من الميل الطبيعي للعدـلاء
فراغك بأما فى إذاكان العميل يعاني من مشكلة عميقة

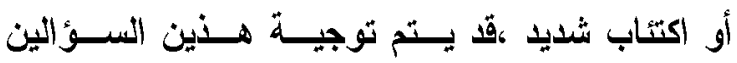

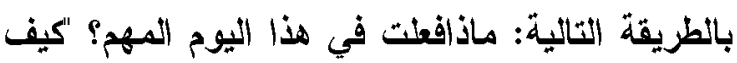

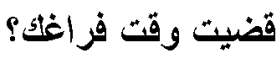
(J ohn Henden, 2008, 77) r- تحديد الهدف : يجب أن تكون أهــاف العميـل

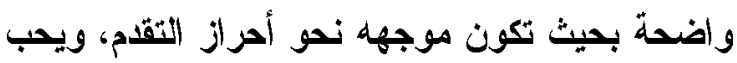

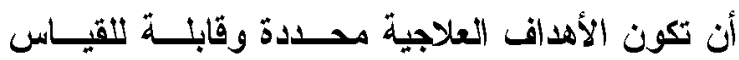
ويمكن تحيقها، وتنقسم الاهداف العلاجية في صياغتها

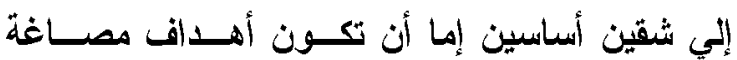

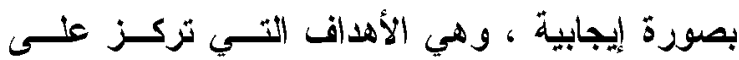

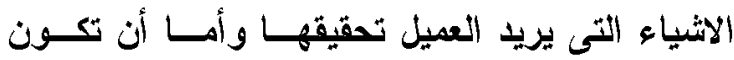
أهداف مصاغة بصورة سلبية وتعبر الاهداف السلبية

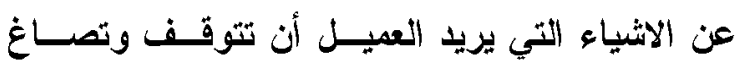

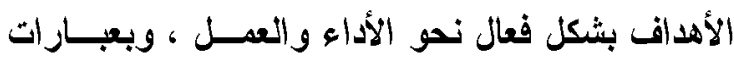

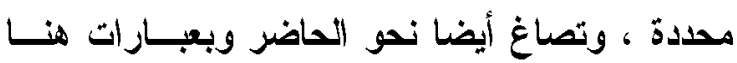
Miller,G\& De والآن.

(Shazer,2000,5- 23 )

r- تفصيل أفضل الآمال أو المستقبل المفضـلـل لــدي العميل: بمجرد تحليد أهــاف العميـل، يــتم طــرح مجموعة من الأسئلة لتمكينه من وصف أفضل الآمال

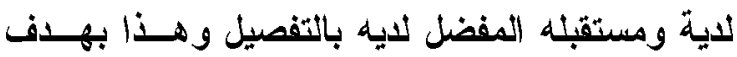
وصف ماستكون عليه حياته عندما نكون المشكلة قد

تم حلها. ؛ - تحديد الاستثناءات أو حالات النجاح: يعتبر البحث

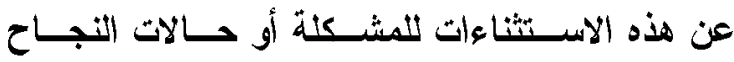

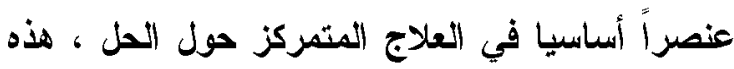
الاستثناءات أو الحالات في كثير من الأحيان تمر دون

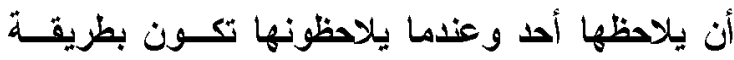
سريعة.

(Alison Nicholas,2014, 210:212) حيث يستخدم المعالج فى العلاج المتمركز حول الحل

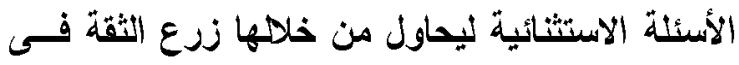

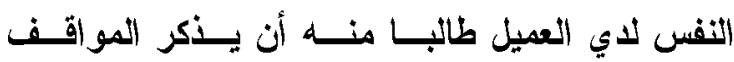

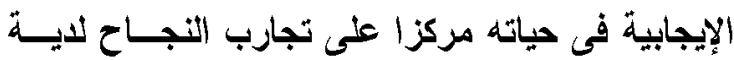


العلاج المتمركز حول الحلل من منظور خدمة الفرد

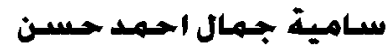

سادسأ- هبادى العلاج المتهركز حول الصل: 1. يعتمد العلاج المتمركز حول الحـلـل علـــ بنــاء الحول بدلا من حل المشكلات

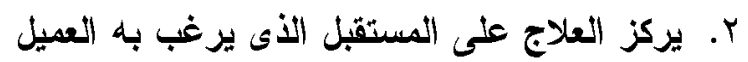

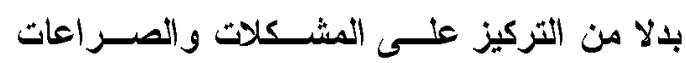
الحالية. r. لا توجد مشكثله تحدث فى جميع الاوقـات ولكـن هناك استثناء) ؛. تثنجيع السلوكيات المرغوبة لدى العيل.

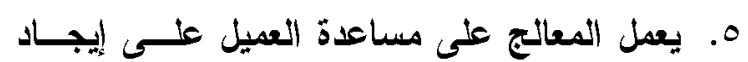
بدائل للسلوكيات الغير مرغوب فيها.

Uohnny S. Kim, Michael S. Kelly, \& Cynthia Franklin, 2017,38:37)

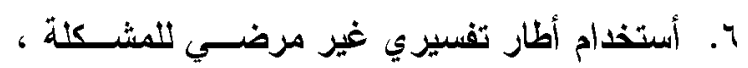

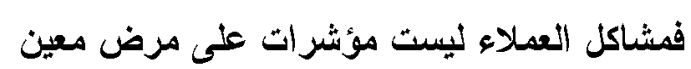

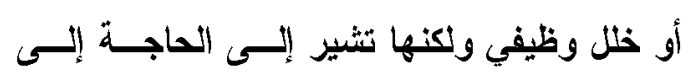
وجهات نظر لحها أوتغيير سلوك العميل.

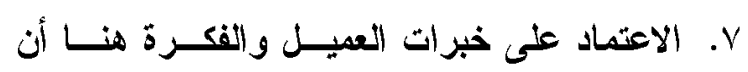
العبيل هو الخبير عن مشكلتة وليس المعالج. A. التزكيز على الموارد المتاحة لدي العميل.

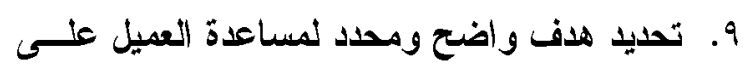

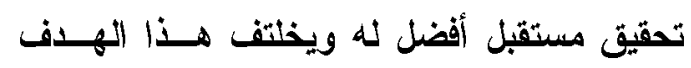
حسب العميل وحسب المشكلة.

(Michael J. Cavanagh and Anthony M. Grant, 2010 ,59)

. ا.فه سبب مشكلة الفرد ليس له أي صلة ضرورية لحها 1ا.التحثث عن المثكنة وأوجه القصور لدى العميل

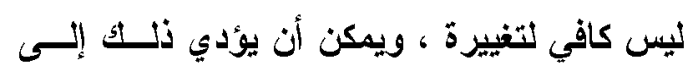

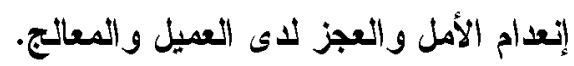
با.الهدف من أسئلة العلاج المتمركز حول الحل هو لهون

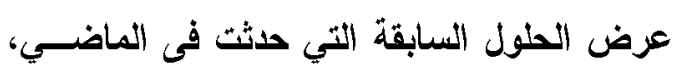

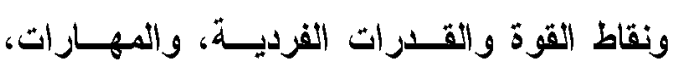
والموارد، وروئية العميل للمسـتقبل ، وبالتــالي

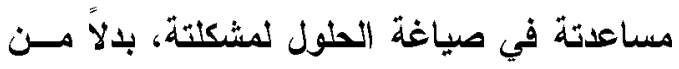

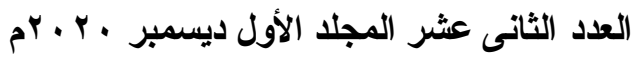

J ohnny S. ) "لمقاومة" التدخل الخارجي". (Kim, Cynthia Franklin,2009,465

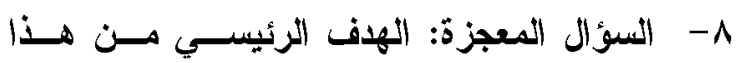
التكنيك هو البحث عن الأستثناءات التى يمكن أن تقود التهدي

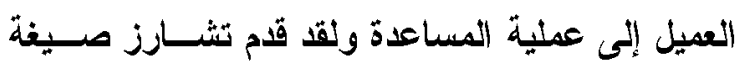

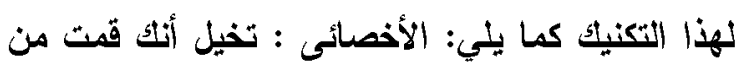

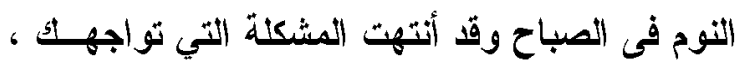

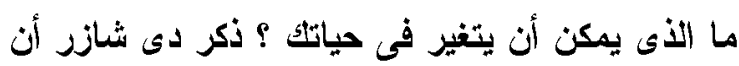

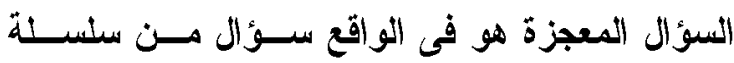

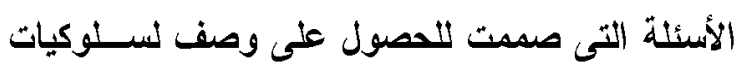

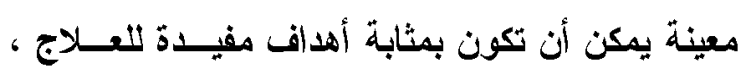

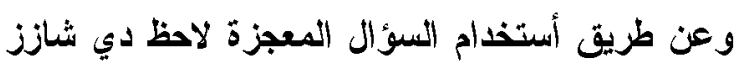
أن المعالجون قادرون على إيجاد أوضح صورة ممكنة

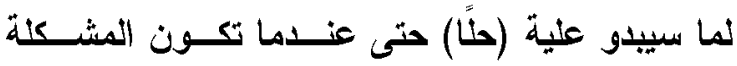
غامضة .

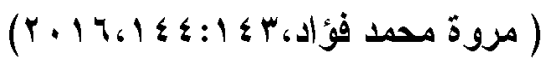
خاهسًا :استزاتيجيات العلاج المتهركز هول الصل: (Linda Seligman, 2004, 208) 1- إعطاء العلاج والمهام للعميل من خــلال روئيتهـ لكأخرين وقز اهته للتغيير.

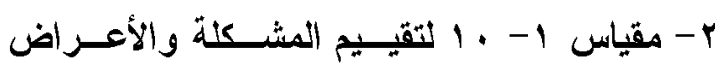
و التقدم لدي العميل . مياسي ب- تغيير السلوكيات المتكررة وغير المنتجة للسلوك ـ- السؤال المعجزة ه- - إعادة صياغة צ- تثجيع أستخدام السلوك الإيجابي الــذي يحسدث بالفعل والتوسع في الاستثناء|ت الإيجابية - V تطوير سلوك جيا وأكثر فائدة للعبيل

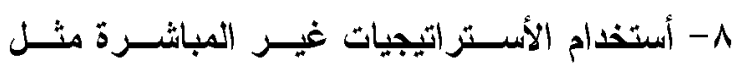

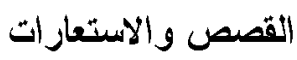
9- فييزيو طويل يتم فيه (وصف المخاوف من حيــث (العدل) . 1 - تقليم المجاملات و التثبيع للعميل 
الخطوة الثانية- تطوير صورة للحل ميع العميل :وتعد

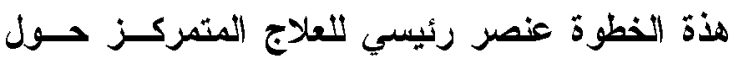

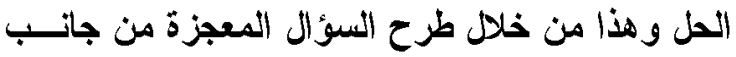

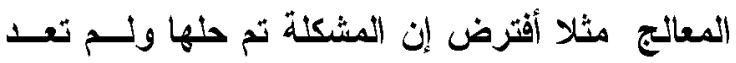
موجودة ، لنفترض أن كل شيء قد تغيــر بالطريقـــة

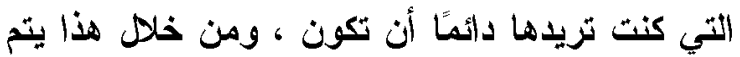

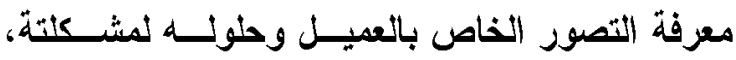

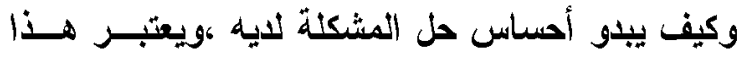

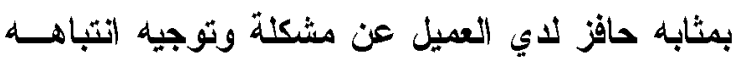
بقوة نحو تحقيق الهدف ، وذلتك بعد ترسـيخ صـــورة

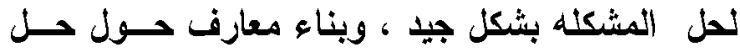
المشكلة بشكل أساسي ، والرغبة في تحقيق الحل لاي

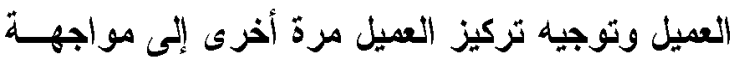

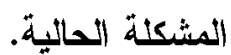

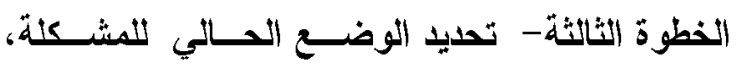
والموارد، والاستثناءات: عن طريق توسـيع نطساق

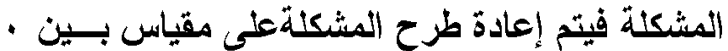

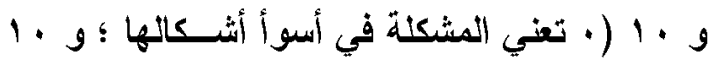
تغني صورة الحل) ، في أي مرحلة ستكون المشــكنة

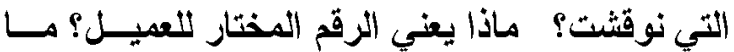

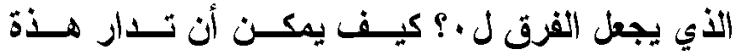

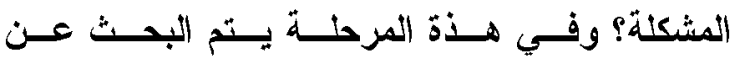

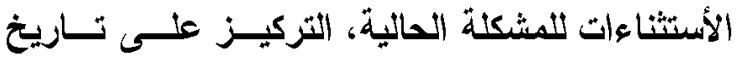
العميل لحل مشاكله، وكيفية تعامل العميل مع الأسئلة

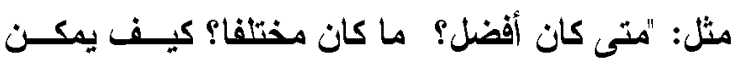

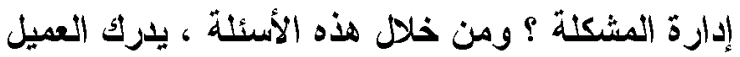
أن المشكلة ليست موجودة بنفس الارجة دائما وبدون

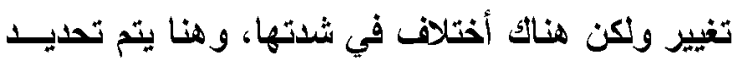
أجز اء لحل المشكلة.

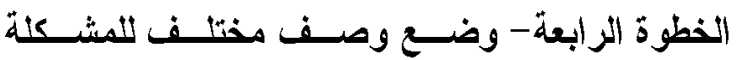
وتعديا الاهداف: بناءًا علي الخطوة السابقة لنفترض

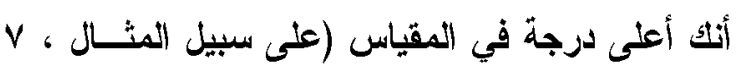
بدلاً سن ج) ما الاختلاف في أن تكون في السابعةٌ ما فا

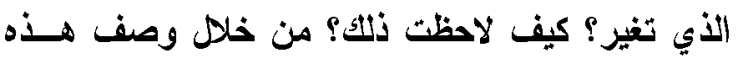

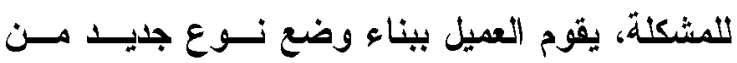

كلة.

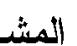
ع التزكي

\section{(Timothy Wand etal; , 2017,775)}

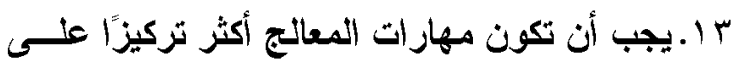
الثر اكة مي العدلاء لبناء

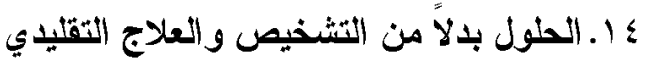
ه . ينصب التركيز على نقاط القوة ويناء الحلول بـلاً

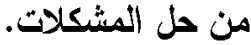
14 ا.فردية العميل حيث كل شخص فريد مسن نوعسه (Daniel S. Sweeney , 2011,65) سابعًا- التدخل المهنى بأستخدام العلاج المتهركز

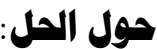
الغرض من التخخلات المتمركـزة حسـول الحـل هـــو المشاركة في بناء حوار علاجي يؤدي إلى عملية بناء الحلول يستخدم المعالجون الأسئلة الموجهة للحطول -

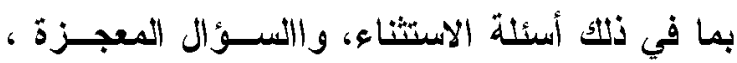

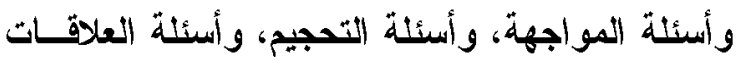

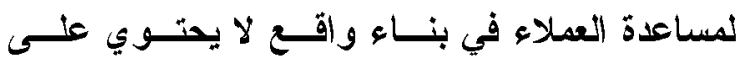
المشكلة، أسئلة الاستفسار تستفسر عن الأوقات التي لئ وني

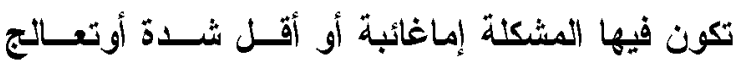
(Francis J. Turner, 2017, بطريقة مقبولـة فئسة

\section{9: 526)}

الخطوة الاولي - وصف المثكلة: في هذه الخطوة ينت توضيح الموضوعات التي سيتم مناقشتها وتوضسيح الأهداف والإجراءات ، وبناء علاقةة مهنية بين المعالج والعميل ، ويركز المعالج فى هذة الخطوة الامنتاع عن

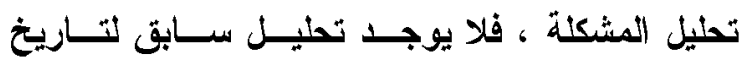

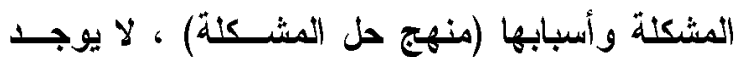
إيضا تحليل موجِّه للأنماط المشكلة ، بينما يتم تسليط

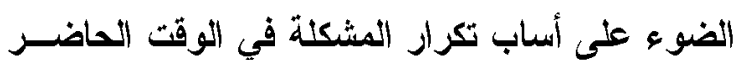

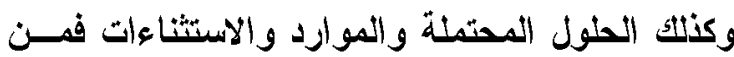
المواضيع التي سيتم مناقشتها وتحيد السياق: ما هو

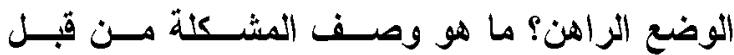
العميل؟ كيف هي مثكلة؟ 
العلاج المتهركز حول الحلل من منظور خدمة الفرد

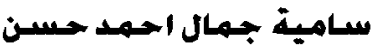

ثاهنًا - المهارات المهنية للاخصائيين الاجتماعيين هن هنظور العلاج المتهركز حول الصل:

يعد مدخل العلاج المتمركز حول الحل SFT خلاصــة لهـ فكرية لجهود عدد من الزواد والمختصين في مجـال

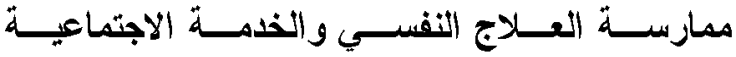
الإكلينيكية، وليس من شك أنه مر بمراحل متتالية من

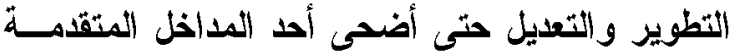
في مجال الممارسة المهنية، ولا بـ للأخصائي الـــي

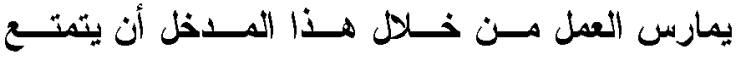
بمجموعة مـن الخصــائص و الصـفـات والمهــارات الخاصة في علاقته مع العملاء وهي : 1. المهارة في معرفة المستقبل المفضل لدي العميل فيل فئل : الجميع لايــة مســتقبل مفضــل والاخصـــئي الاجتماعي هنا يحتاج إلى تثجيع العميل لتصــور

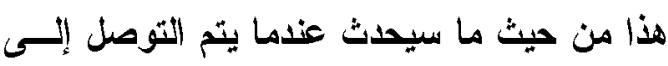

هذا المستقبل ، ما الأي سيكون مختلفا لديه ؟ هنئ r. المهارة في البحث عن الاستثناءات والاختلافات:

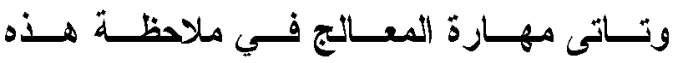

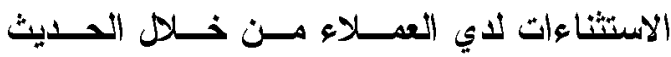
|القصصي ولتلاك يجب الاستماع بغناية فائقــه حتـــ لا تذــوت عليهم. r. المهارة في أستخدام السؤال المعجزة :الســؤال

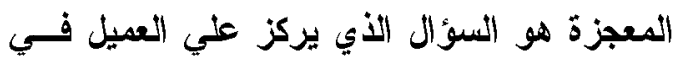

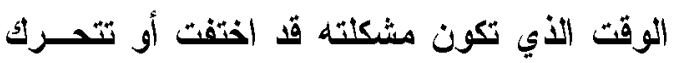
لبثء الحديث مع العميل نحو مستقبله المفضل.

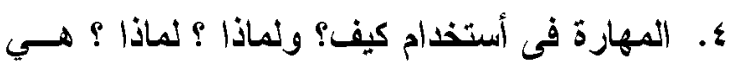

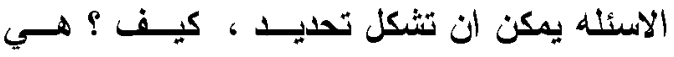

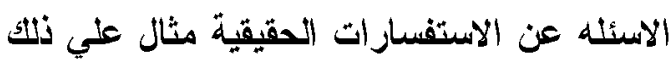
:لماذا تعتقا ان الحصول علي الكـــول سـيكون جيا للك ؟"كيف تعتقد الحصول علي الكحول هــو

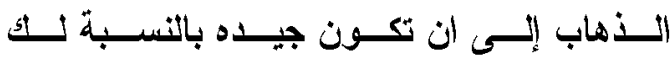

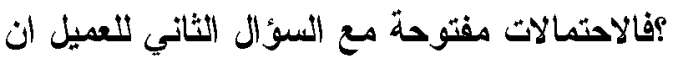
تكون وصـفيه جـا وهــا مــا يبحـث عنــه
الأهداف المحددة له، ولذلأك من المهح بما فيه الكفاية

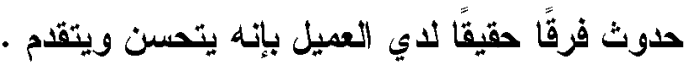

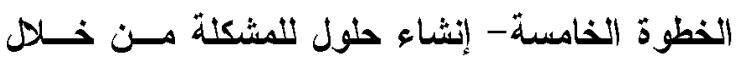

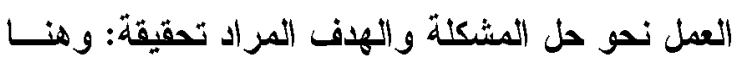

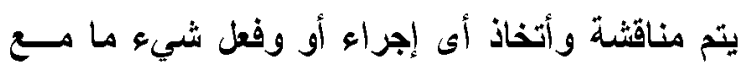

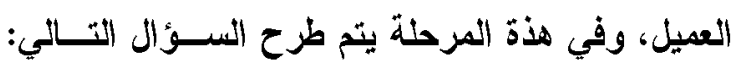

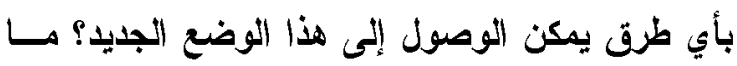

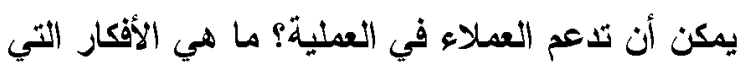

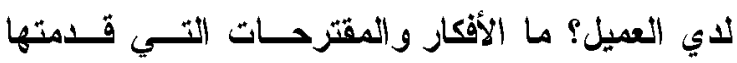
المعالج قد تدعم العميل؟ ففي هذة المرحلة يتم مناثثة

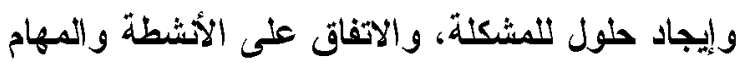

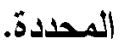

\section{James H. Bray and Mark Stanton,} (2009, 215) ومن وجهة نظز أخرث حددت الخطوات التالية للعلاج المتمركز حول الحل فيما يلي: ا. محادثة بين المعالج والعميل لمعرفة المزيد عـن هئن حياة العميل r. جمع وصف موجز للمثكلة r. طرح أسئلة لتكوين العلاقة المهنية ؛. ت. تبع الاستثناءات للمثكلة ه. توسيع نطاق المثكنة 7. أستخدام أسئلة المواجهة المئة

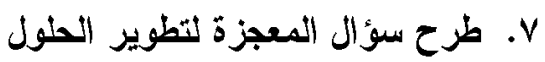
^. التفاوض على هدف التثغييز

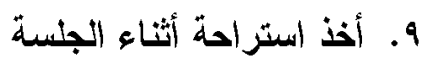

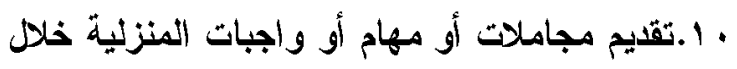
عملية التدخل، يحدد المعالج المشكلة والإمكانات

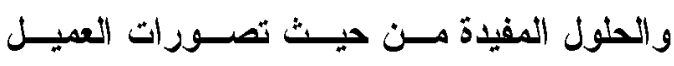

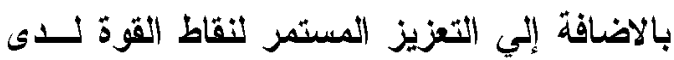

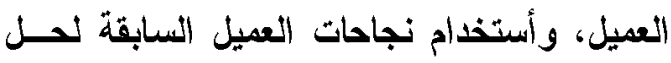

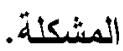

(Laura M. Hopson etal;, 2004, 98) 
العلاج المتهركز حول المل من منظور خدمة الفرد

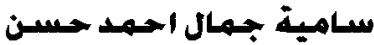

وهن وجهة نظر أخري تتضمن المهــارات المهنيـة للعلاج المتمركز حول الحل :

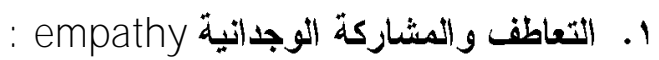

وفيها يظهر اهتمام المعالج بالعميل من خلا

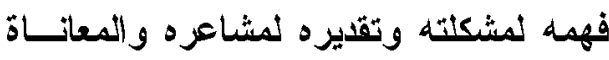
التي يشعر بها.

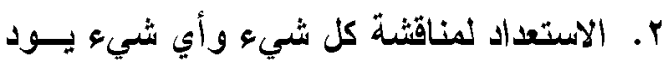

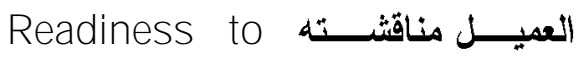
discuss everything

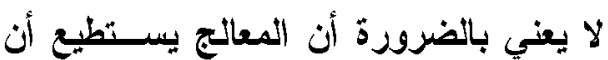

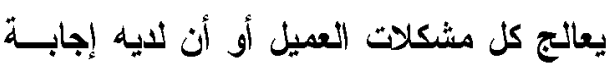

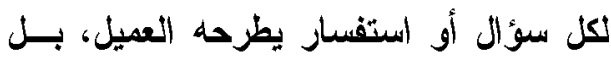

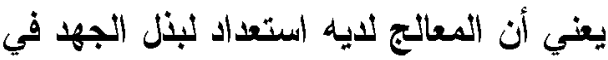

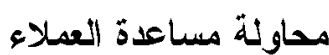
r. الهدوء Composure :وتعني أن يكـون

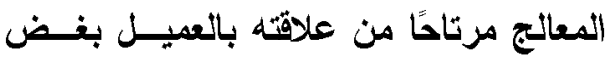

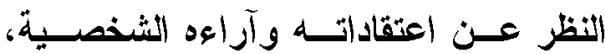

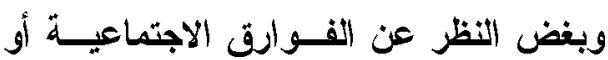
الاقتصادية أو العرقية أو غيرها فالعميل في نهاية المطاف إنسان يجب احتر امه والاهتمام

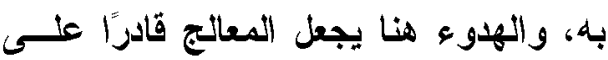
التركيز في كل ما يقوله أو يشعر به العميل.

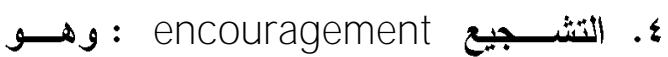

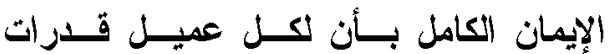
و إمكانيات يستطيع استثمارها إلى أقصى حـ

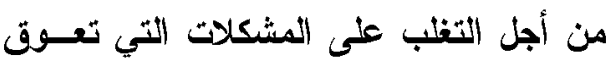
تكيفه النفسي والاجتماعي، وثيام الأخصائي

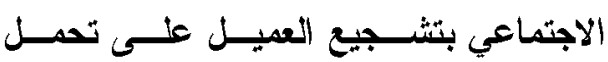

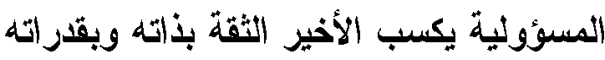

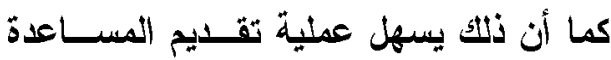

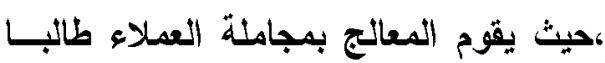

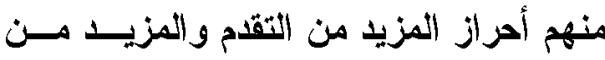
التغييز حتي ولو كان بسيط. ه. تحيد الأهداف: وتعني أن يكون الأخصـائي

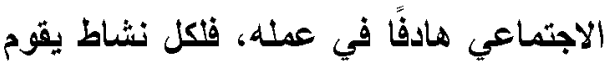

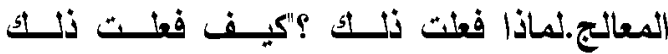
؟"الاحتمالات مفتوحة مع السؤال الثـاني للنــاس فئس

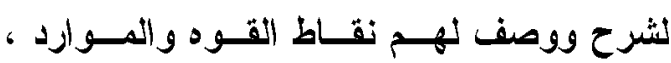
والخطوات التي اتختنها والتي كانت مفيده، "كيف ؟" أو "كيف تاتي ؟" يبدو أفضل بالنســة لاســئلة (Paul Hanton , 2011,22:30) . المعالج ه. المهارة في الحديث بـدون مشــاكل: المهــارة

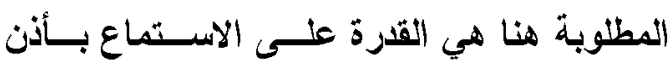
مفتوحة ، و التحدث بصر احة

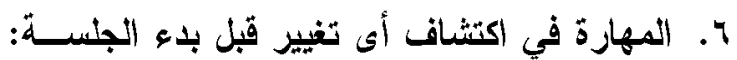
حيث تتغير الأمور من شنهر الحى شهر ومن يــوم

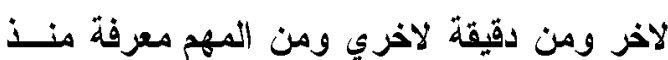

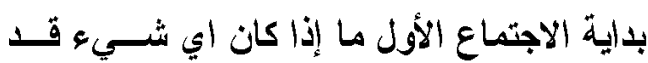

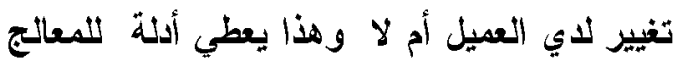

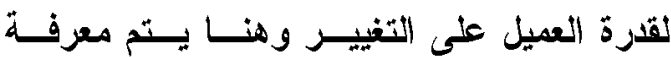

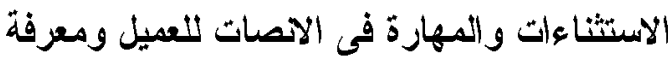

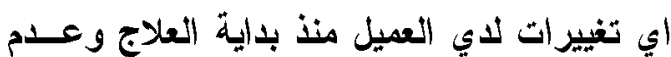
نسيانها. v. المهارة في التفاوض نحو المستقبل المفضل لدي العميل :التفاوض هو قرة المعالج على تحديــ الاهداف العلاجية مع العميـل والاتفــاق عليهــــا للوصول الي المستقبل المفضل لايه

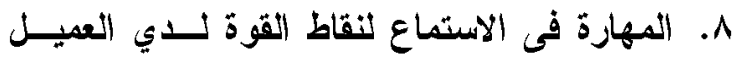
ومواردة ومهار اتــة : تعــــ مهــارة الاخصــائي

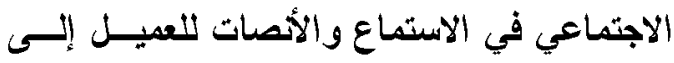
اكتثاف الموارد ونقاط القوة لديه ومهاراتة التي لالتي يمكن ان تساعدة في الوصول إلي حل .

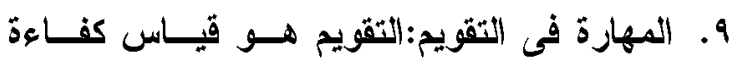
وفعالية الممارسة في تحقيق الأهداف المرجــوة فئسئ

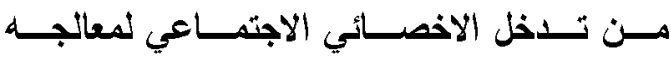

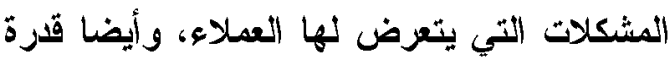
الأخصائي علي حصـر الأيجابيـات والســلبيات وتطوير الايجابيات وتحويل السلبيات إلــي نقــاط إيجابية. ( 14, 2001, (Bill 0' Connell) 
العلاج المتهركز حول الملل من منظور خدمة الفرد

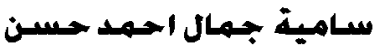

ه. القدرة على احداث تغييرات خلال ثلاثة أو اربــع

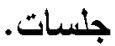

צ. . مرونة العلاج طبقا لاختلاف كل عميل عن الاخر.

(Anao Zhang etal; 2017,104)

V. التركيز عذي مهارات العميل بدلا مـن التركيـز على نقاط العجز لايه.

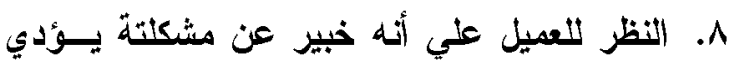

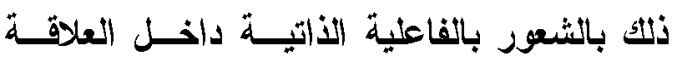

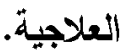

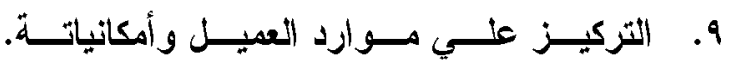
(J ohn M. Roeden etal; 2009, 255) • عيوب العلاج المتمركز حول الحل:

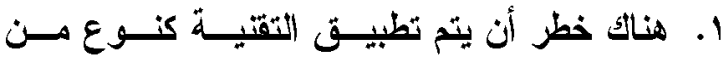
الإصلاح السريع. r. من الضروري الاخصائيين الاجتمــاعيين الـــين يأملون في توظيف هذه الأساليب أن يتعودوا على الاجنى إعادة صياغة المواقف والاستماع للعملاء. r. الايز ال العلاج يتطلب تحليلا دقيقا. ع. إيجاد حل قبل معرفة أي شيءعن مشـكلة. قــــ ينتج عنه عمل مشوش لايكون متأكسين مدسا

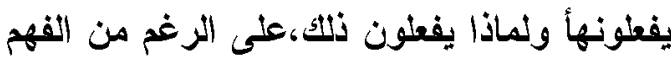
الصحيح لهذه العلاج ، فإن العلاج المتمركز حول

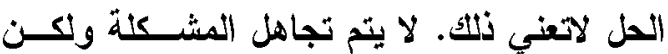

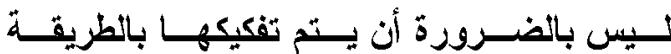

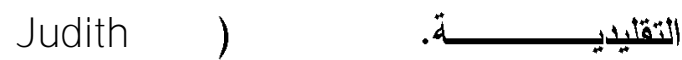
Milner\&Patrick Byrne ,1998,160:

ه. قالة الدراسات التى استخدامت مجموعات المقارنة

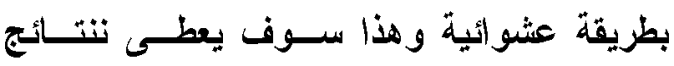
ومقاييس قوية. צ. عدم وجود در اسات تجريبية.

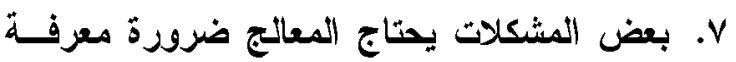
التاريخ التطورى للمشكثة.

(Kitty L. Brasher, 2009, 21)
به هدف وغاية يسعى إلى تحقيقهًا وتخــدم

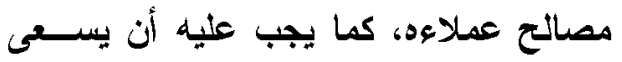
إلى توضيح ذلاك للعدلاء الذين يتعامل معهم،

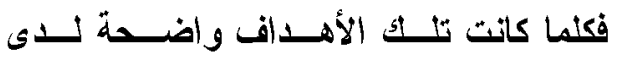
الأخصائي و العميل كلما كان ذلتك أدعـى لأن تصبح عملية المساعدة أكثر كفاعة وفاعلية.

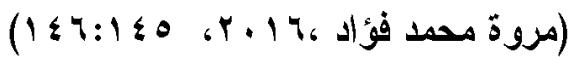
وفى ضوء هذة المهارات تكون العلاقة المهنية تبادلية

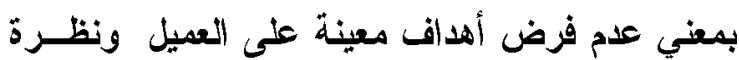

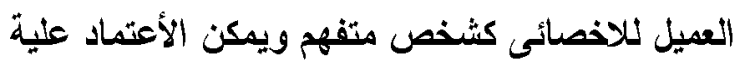

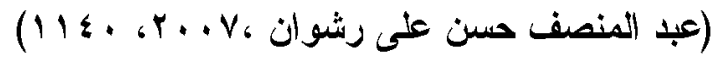
تاسعًا- فاعليـة أسـتفدام العـلاج المتهـركز هـول الهل هم العملاء: تزجع فاعلية وتاثير العلاج المتمركز حول الحل إلـــ

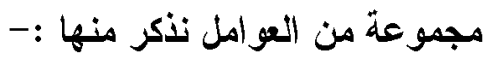

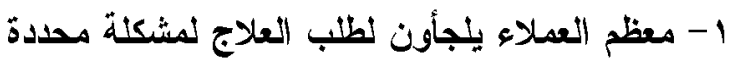
يواجهونها وليس من أجل العصول علـــ استبصــار بتأثير ها فقط. r- معظم العملاء يطلبون المساعدة ويتوقمون النتائج العاجلة التى لا تستنزف الوقت و الجهد.

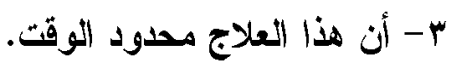
؟- يتميز العلاج بالو اقعية والتركيز علــ الحاضـــر و النشاط الموجه . ه- أن هذا العلاج يندرج في الوصول إلى الاهداف.

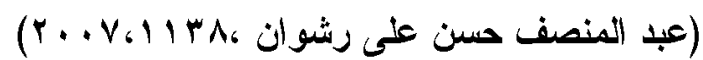
عاشراً- هرايا وعيوب العلاج المتهركز حول الهل: • مزايا العلاج المتمركز حول الحل: 1. التركيز على الاستماع للعملاء. r. التركيز على الاستثناءات. r. بقلل من مخاطر الممارسة ويزيد من الإبداع. J udith ) ؛. يتمحرر العلاج حول العميـل.

Milner\& Patrick Byrne, 1998,160: 
العلاج المتهركز حول المل من منظور خدمة الفرد

سـامية جمال احمد حسن

Perspectives

on

autism

Identification,

assessment,

problems, intervention, and instruction,Arees University Press.

Bill O'Connell (2001): Solution .A

Focused stress Counselling,

London, SAGE Publications Ltd

Caroline

Bond

etal;(2013):Practitioner Review: The effectiveness of solution focused brief therapy with children and families :a systematic and critical evaluation of the literature from 1990-2010, Journal of Child

Psychology and Psychiatry54:7

Cunningham, Kenneth $\quad .1$

(2011):Development and Validation

of a Measure to Identify the

Predictors of Recovery-Oriented

Practice among Social Workers in

Public Mental Health and Addiction

Agencies ,PhD , University of

Connecticut, Klein. Waldo

Cynthia Franklin and Anao .11

Zhang(2016): Solution- Focused

Brief Therapy A systematic review and Meta-summary of process Research , Journal of Marital and Family Therapy

Elnora D. Cunanan(2003):What . Ir

Works when learning solution focused brief therapy,A Q ualitative analysis of trainees experiences, , Thesis been provided to meet in

\section{المجلة العلمية للخدمة الاجتماعية

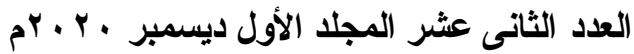

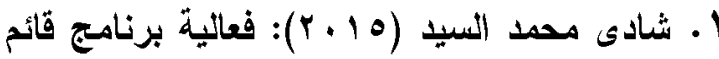

على العلاج المختصر المتمركز حول الحـلـل فـي

تحسين مستوى تقدير الذات لدى التلاميـــ ذوي

صعوبات التعلم، مجلة التزبية الخاصــة ،مركـز لهزئ

المعلومات التربوية و النفسية و البيئيـة ،جامعـة

الزقازيق ،كليه التربية ، العدد الحادى عثر .

Y. عبد المنصف حسـن رثــوان ،محمــ مسـفز

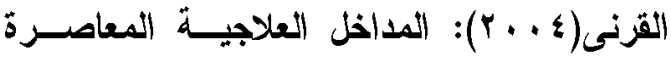

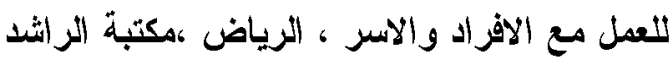

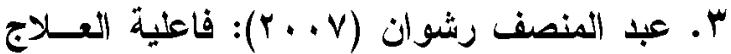

المتمركز حــول العـل فــ تعقيـق المســاندة

الاجتماعية لطلاب الجامعـة ،المــؤتمر العلمـي

الاولي العشرون للخدمة الاجتماعية ،كلية الخدمة

الاجتماعية جامعة حلوان.

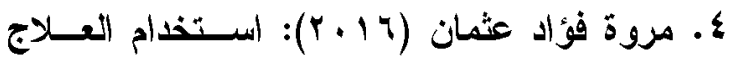

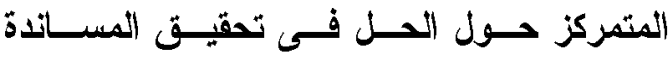

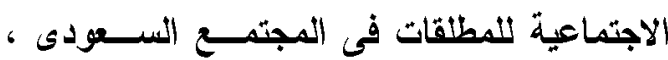

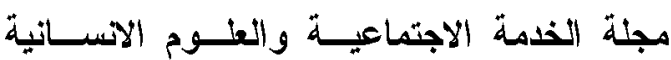

،الجزء السابع ،العدد السادس والخمسون .

๑. مسعد بنى غنام (10 + ץ):" مدخل العلاج الموجز

الذى يركز على الحل ،مجلة العــوم الانســانية

والخدمة الاجتماعية ،العدد الرابع والخمسون.

7. S. Smtth (2009): A preliminary .7 analysis of narratives on the impact of training in solution-focused therapy expressed by students having completed a 6-month training course, Journal of Psychiatric and Mental Health Nursing, Blackwell Publishing Adel Abdulla, M.\& Mourad, A. .V Eissa (2014): Contemporary 
العلاج المتمركز حول المل من منظور خدمة الفرد

سمامية جمال احمهد حسن

Focused Approach ,J ohn Wiley \&

Sons Ltd.

John Rhodes and Yasmin .19

Ajmal(1995):Solution Focused

Thinking in Schools, BT Press

,London

J Ohn Wheeler (2001): A Helping . . .

Hand: Solution- Focused B rief

Therapy and Child and Adolescent

Mental Health, Clinical Child

Psychology and Psychiatry (6)2.

Johnny S. Kim \&Cynthia .Y

Franklin (2009): Solution-focused

brief therapy in schools: A review of the outcome literature, Children and Youth Services Review, Volume

31.

Johnny S. Kim (2014): .YY

Solution- Focused Brief Therapy and Cultural Competency, Solutionfocused brief therapy : a multicultural approach, SAGE Publications, United States of

America

J ohnny S. Kim, Michael S. Kelly, .YT

\& Cynthia Franklin(2017): SFBT and Evidence- Based Practice The State of the Science, SolutionFocused Brief Therapy in schools, , Oxford University Press, United States of America, second edttion . Judith Milner\& Patrick Byrne . Y (1998):Assessment in Social Work, London ,Macmillan.

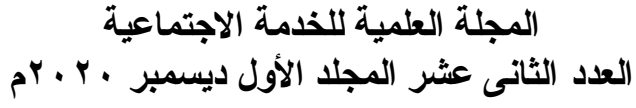

fulfillment of the requirements for the degree of Master of science in human development at Virginia Polytechnic Institute and State University,USA

F. P. Bannink (2007): Solution- . I Springer ,Focused Brief Therapy Science.

Fredrike Bannink (2010):1001 . I solution-focused questions : handbook for solution-focused interviewing, United States of America

Harvey Ratner etal;(2012): .10 Solution Focused Brief Therapy 100 Key Points and Techniques ,Routledge, 3

Helen Lloyd\& Rudi Dallos(2008): . 17 First session solution- focused brief therapy with families who have a child with severe intellectual disabilities, mothers' experiences and views, Journal of Family Therapy 30: 5-28 Ian Smith; (2011): A qualitative . IV investigation into the effects of brief training in solution-focused therapy in a social work team, Psychotherapy: Theory Research and Practice.

John Henden (2008): What is .11 Solution Focused Brief Therapy ,Preventing Suicide: The Solution 
العلاج المتهركز حول المل من منظور خدمة الفرد

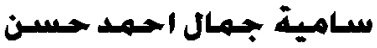

Wei Zhang etal; (2014): Brief .rr

Report: Effects of Solution- Focused

Brief Therapy Group-Work on

Promoting Post- traumatic Growth of Mothers Who Have a Child with ASD, Springer Science+Business

Media New York.

Woods,etAL (2010): systematic .rr

Review of solution-focused brief therapy with children and families ,research report Dfe RR179, university of Manchester.
المجلة العلمية للخدمة الاجتماعية

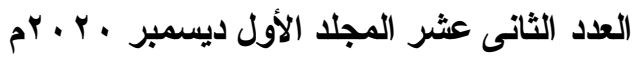

Kevin Corcoran, Albert R. .ro

Roberts (2015): Social Workers'

Desk Reference,New York, Oxford

University Press.

Kitty L. Brasher (2009): .Y५

Solution-Focused Brief Therapy

Overview and Implications for

School Counselors, The Alabama

Counseling Association Journal,

Volume 34, Number 2, Spring.

Laura M. Hopson, MSSW, .rV

Johnny S. Kim, MSW(2004): A

Solution-Focused Approach to

Crisis Intervention with

Adolescents, Journal of Evidence-

Based Social Work, The Haworth

Press

(2004): Linda Seligman .r

Diagnosis and Treatment Planning

in counseling, Springer Science \&

Business Media.

Michael J. Cavanagh and . rq

The :Anthony M. Grant (2010)

Solution-focused Approach to

Coaching ,London, Los Angeles.

Miller,G\& De Shazer(2000): .r.

Emotions in solution Focused

therapy ,A reexamination, family

process, 39, 1

Trepper, W.J. Gingerich \&E.E. .TI

McCollum (2012): Solution- focused

Brief Therapy; A Handbook of

Evidence- Based Practice, New

York: Oxford University Press. 